\title{
Salient features of color space
}

\author{
T. W. A. WHITFIELD \\ School of Industrial Design, Leicester Polytechnic, Leicester LEI 9BH, England
}

\begin{abstract}
Recent research has demonstrated that focal regions of color space are cognitively more salient than nonfocal regions. Employing a linguistic hedge task, the experiment here sought mainly to verify the cognitive primacy of foci representing Berlin and Kay's first four chromatic categories over foci representing the remainder. The experimental results failed to support the primacy hypothesis, an outcome that gives rise to a number of theoretical implications. Additional questions in the analysis concerned the relationship between the salience of a color and its lightness (Munsell value) and saturation (Munsell chroma). While the results permit no simple interpretation for lightness, a definite trend emerged in the case of saturation.
\end{abstract}

Color space was once considered a uniform domain that languages could partition arbitrarily into any number of color categories (Brown \& Lenneberg, 1954; Ray, 1953). Berlin and Kay (1969), however, challenged this view, contending that color space could be partitioned into a maximum of 11 basic color categories-three achromatic and eight chromatic-each defined by its own focal region. They further contended that focal regions were remarkably similar for speakers of all languages that encode a particular color category.

In a development of this work, Rosch (1973; see also Heider, 1971, 1972) has since demonstrated that focal regions possess greater cognitive salience than nonfocal regions. Effectively, focal colors are better remembered than nonfocal colors, and color categories structured around foci are more easily learned than categories structured in other ways. Investigating developmental implications, Mervis, Catlin, and Rosch (1975) have also shown that category foci become established and are stabilized earlier than category boundaries, while Rosch (1975) has drawn further attention to the cognitive status of foci as reference points to which other category members are judged (Rosch has since extended this work to provide a more comprehensive statement regarding the structure of both perceptual and semantic categorization: see Rosch, 1977; Rosch \& Mervis, 1975; Rosch, Mervis, Wayne, Johnson, \& Boyes-Braem, 1976; Rosch, Simpson, \& Miller, 1976).

A question that has received little attention, however, concerns the relative salience of the eight chromatic foci. The only study to have directly addressed

This work was a part of a research program sponsored by the Science Research Council (Great Britain) while the author was at the Building Science Section of Newcastle University. Address correspondence to T. W. A. Whit field, School of Industrial Design, Leicester Polytechnic, Leicester LE1 9BH, England. this particular question was carried out by Heider (1972). This study tested two hypotheses. The first was that codability and memorability for the eight chromatic foci would follow Berlin and Kay's (1969) evolutionary order-a plausible hypothesis, given that the natural salience of foci may determine the learning and, hence, linguistic evolution of basic color terms. The second hypothesis was that codability and memorability would be greater for foci of Berlin and Kay's first four chromatic categories (red, yellow, green, and blue) than for the remainder (orange, pink, brown, and purple)-again, a plausible hypothesis, given that the former may be physiologically salient (De Valois \& De Valois, 1975; Walraven, 1973). Heider's experimental results, however, fail to support the first hypothesis, while providing only partial support for the second. The inconclusive nature of the latter outcome, reinforced by an inspection of the actual rank orders obtained, gave rise to the present study. In this study, the main question of interest concerned the relative salience of the two sets of chromatic foci. Two subsidiary questions concerned the relationship between the salience of a color and its lightness (Munsell value) and saturation (Munsell chroma).

In order to determine the salience of a stimulus, both a theoretical and an operational definition of salience were required. Following Rosch (1975) and Tversky (1977), the salience of a stimulus was equated with its referential status and defined as the degree to which it constitutes a reference point within a category. The operational definition required the demonstration of asymmetric distance relations between reference and nonreference stimuli. Rosch (1975) has justified the asymmetry criterion on the grounds that stimuli deviant from a reference point should be "more easily assimilated to and, thus, judged metaphorically 'closer to' the reference stimuli than vice versa." To test for asymmetry, Rosch used two 
procedures; one was spatial, in which subjects determined the relative physical locations of pairs of stimuli, while the other was linguistic, in which subjects located pairs of stimuli within a linguistic hedge (Lakoff, 1972). Evidence of asymmetric distance relations was obtained for three sets of stimuli: colors, line orientations, and numbers. (Further evidence of such asymmetries is available in Handel \& Garner, 1966; Lee, 1970; Tversky, 1977; Whitfield \& Slatter, 1979.)

Following Rosch (1975), the present study employed a linguistic hedge task. In this, subjects were required to place pairs of stimuli (color chips that differed slightly from one another, e.g., a "pure" blue and an "off" blue) into blanks of the sentence frame "__is almost_." Given the logic of natural languages, the stimulus of lower reference status should be placed in the first blank and the stimulus of higher reference status in the second. (See Rosch, 1975, for a more detailed description.)

It may be noted that the present study differed from that conducted by Rosch (1975) in certain important respects. These lay in (1) the range of color stimuli employed, (2) the control exercised over the psychophysical properties of the stimuli, and (3) the control exercised over the differences between members of color pairs.

(1) Rosch's color sets were limited to one huevarying and one chroma-varying set, with the former covering the first four of Berlin and Kay's chromatic categories. The present study employed five sets: two hue-varying, which covered all eight of Berlin and Kay's chromatic categories, two chromavarying, and one value-varying set.

(2) It is a feature of Rosch's study that the huevarying set-which, theoretically, varied only in huein fact varied on dimensions other than hue. This variation is systematic for the chroma dimension, whereby reference members of each pair were of higher Munsell chroma than nonreference members. As elsewhere in the study, Rosch demonstrated that increased chroma enhanced the referential status of a color, then the results of the hue test appear confounded by probable chroma effects.

(3) While not critical to Rosch's work, the present study controlled differences within stimulus pairs to maintain equal perceptual differences within each set. Although these differences were necessarily approximate, due to irregularities within the Munsell system (Padgham \& Saunders, 1975), they were considered adequate to permit comparisons to be made between subjects' performances on relevant sets (e.g., between the two hue-varying sets).

\section{METHOD}

\section{Subjects}

The subjects were 48 personnel (clerical staff), 19 males and 29 females between 18 and 55 years of age, from the Central Office of the Department of Health and Social Security, Newcastle upon Tyne. The subjects were selected from a population of approximately 13,000 on the basis of proximity to the room in which the experiment was conducted. This procedure placed selection outside the experimental control. All the subjects were volunteers, and none had previously taken part in a laboratory study. The Ishihara (1969) test was used to screen for color vision anomalies.

\section{Stimuli}

The stimuli were a sentence frame and a set of color chips. The sentence frame used the hedge "_-is almost_." This was centered (Letraset) on an $11.5 \times 32 \mathrm{~cm}$ white card (N8.5). The color stimuli were $326.5 \times 7.5 \mathrm{~cm}$ Munsell chips (glossy). The 32 mounted chips were used to generate 20 pairs, which were selected to test hypotheses relating to Munsell hue, value, and chroma. Members of each pair were systematically related to provide five distinct sets.

\section{Hue Tests}

In Sets 1 and 2, Munsell value and chroma were held constant, with hue varying. Pairs were selected in which Stimulus 1 was considered to "best represent" the category of red, yellow, green, and blue (Set 1) or pink, brown, orange, and purple (Set 2). These reference stimuli were based on estimates of focality derived from Berlin and Kay (1969) and Heider (1972). The distance between the reference stimulus and its deviate (Stimulus 2) was maintained at five Munsell hue steps.

\section{Chroma Tests}

In Sets 3 and 4, Munsell hue and value were held constant, with chroma varying. Pairs were selected in which Stimulus 1 was 4 chroma steps higher than its deviate (Stimulus 2). The purpose of employing two sets of pairs was to investigate chroma effects at two distinct levels of chroma.

\section{Value Test}

In Set 5, Munsell hue and chroma were held constant, with value varying. Pairs were selected in which Stimulus $I$ corresponded in Munsell value to the focal point of the category (Berlin \& Kay, 1969). Of the four color pairs in the set, the value of the discrepant stimulus (Stimulus 2) was lower than the focal value for two of the pairs and higher for the other two pairs. Value differences were maintained at two steps within each pair.

\section{Apparatus}

The stimulus material was viewed within an enclosure $102 \times$ $82 \times 60 \mathrm{~cm}$ in size. The illuminant employed conformed with the standard provided in British Standards Institution (1967). (This corresponds to CIE Standard Illuminant D6500.) Illumination level was controlled at $1,000 \mathrm{~lx} \pm 80$, with surrounds $\mathrm{N} 6.5$ (matt).

\section{Procedure}

The subjects were tested singly. Each subject performed the linguistic hedge task for all five sets of color pairs. The order in which pairs were presented was randomized for each subject. The left-right order of colors in each pair was counterbalanced across subjects.

It was found from pilot work that once subjects understood the requirements of the linguistic hedge task, little difficulty was experienced in making a number of such judgments (cf. Rosch, 1975). The subjects were initially given written instructions. These were then supplemented by verbal instructions and illustrative examples. The latter were either geographic or numeric and borrowed from Tversky (1977) and Wertheimer (1938). Only when subjects were satisfied that they understood the task requirements did the actual experiment commence. The average session lasted approximately $25 \mathrm{~min}$.

\section{RESULTS}

The main question of interest in the analysis con- 
cerned the relative salience of the two sets of chromatic foci. Two types of analysis were performed. First, binomial tests were used to verify differences between observed and expected proportions (.5) of scores for each stimulus pair. The results are given in Table 1. These reveal that, with the exception of the blue pair, the referential status of Stimulus 1 was confirmed in both hue sets. Since the score for the blue pair was in the predicted direction and would achieve significance at the $5 \%$ level, its inclusion as confirmatory would seem justified. To test for difference between the two hue sets, the number of "correct" placements in each set per subject was used as a matched score in the calculations of a Wilcoxon signed-rank test (Hollander \& Wolfe, 1973). Using a two-tailed test, the result failed to reject the null hypothesis of no difference between scores in each set $(z=-.36, p=.73)$.

The results of the binomial tests performed on the two chroma-varying sets provide confirmation of Rosch's (1975) findings. In effect, increased chroma enhanced the referential status of the colors. The position is less clear, however, with regard to the role of value. In the value-varying set, the referential status of Stimulus 1 was only confirmed for those two pairs (1 and 4) in which Stimulus 2 was

Table 1

Placements of Color Stimuli in the Linguistic Hedge

\begin{tabular}{|c|c|c|c|c|c|}
\hline Pair & \multicolumn{2}{|c|}{ Stimulus 1} & \multicolumn{2}{|c|}{ Stimulus 2} & $\mathbf{P}$ \\
\hline \multicolumn{6}{|c|}{ Set 1 : Hue Varying } \\
\hline 1 & $5 R$ & $4 / 14$ & 10RP & $4 / 14$ & $.81 *$ \\
\hline 2 & $2.5 \mathrm{Y}$ & $8 / 12$ & $7.5 \mathrm{Y}$ & $8 / 12$ & $.79^{*}$ \\
\hline 3 & $2.5 \mathrm{G}$ & $5 / 10$ & $7.5 \mathrm{G}$ & $5 / 10$ & $.73 *$ \\
\hline 4 & $2.5 \mathrm{~PB}$ & $4 / 10$ & $7.5 \mathrm{~PB}$ & $4 / 10$ & .65 \\
\hline \multicolumn{6}{|c|}{ Set 2: Hue Varying } \\
\hline 1 & $5 R$ & $8 / 6$ & $10 \mathrm{R}$ & $8 / 6$ & $.75^{*}$ \\
\hline 2 & SYR & $3 / 6$ & $10 \mathrm{YR}$ & $3 / 6$ & $.73 *$ \\
\hline 3 & $2.5 \mathrm{YR}$ & $6 / 14$ & $7.5 Y R$ & $6 / 14$ & $.77^{*}$ \\
\hline 4 & $7.5 \mathrm{P}$ & $3 / 10$ & $2.5 \mathrm{RP}$ & $3 / 10$ & $.79 *$ \\
\hline \multicolumn{6}{|c|}{ Set 3: Chroma Varying } \\
\hline 1 & $5 R$ & $4 / 14$ & $5 \mathrm{R}$ & $4 / 10$ & $.90^{*}$ \\
\hline 2 & $2.5 \mathrm{Y}$ & $8 / 12$ & $2.5 \mathrm{Y}$ & $8 / 8$ & $.92 *$ \\
\hline 3 & $2.5 \mathrm{G}$ & $5 / 10$ & $2.5 \mathrm{G}$ & $5 / 6$ & $.87 *$ \\
\hline 4 & $2.5 \mathrm{~PB}$ & $4 / 10$ & $2.5 \mathrm{~PB}$ & $4 / 6$ & $.77^{*}$ \\
\hline \multicolumn{6}{|c|}{ Set 4 : Chroma Varying } \\
\hline 1 & $5 \mathrm{R}$ & $4 / 10$ & $5 R$ & $4 / 6$ & .65 \\
\hline 2 & $2.5 Y$ & $8 / 8$ & $2.5 \mathrm{Y}$ & $8 / 4$ & $.96^{*}$ \\
\hline 3 & $2.5 \mathrm{G}$ & $5 / 6$ & $2.5 \mathrm{G}$ & $5 / 2$ & $.75^{*}$ \\
\hline 4 & $2.5 \mathrm{~PB}$ & $4 / 6$ & $2.5 \mathrm{~PB}$ & $4 / 2$ & $.75^{*}$ \\
\hline \multicolumn{6}{|c|}{ Set 5: Value Varying } \\
\hline 1 & $5 \mathrm{R}$ & $4 / 12$ & $5 \mathrm{R}$ & $6 / 12$ & $.92^{*}$ \\
\hline 2 & $2.5 \mathrm{Y}$ & $8 / 10$ & $2.5 \mathrm{Y}$ & $6 / 10$ & .52 \\
\hline 3 & $2.5 \mathrm{G}$ & $5 / 8$ & $2.5 \mathrm{G}$ & $3 / 8$ & .62 \\
\hline 4 & $2.5 \mathrm{~PB}$ & $4 / 8$ & $2.5 \mathrm{~PB}$ & $6 / 8$ & $.90^{*}$ \\
\hline
\end{tabular}

Note-P $=$ proportion of subjects who selected Stimulus 1 as reference point. $\quad * p<.001$ (one-tailed test). of higher value. No difference emerged for the remaining two pairs in which Stimulus 2 was of lower value.

\section{DISCUSSION}

Excluding those for the value-varying set, the experimental results permit a fairly straightforward interpretation. First, and in line with Rosch, cognitively salient stimuli exist for color. Second, salience is partly determined by chroma. Third, salient stimuli (category foci) do not exist solely for the socalled "primary" chromatic categories (red, yellow, green, and blue) but cover the "secondary" chromatic categories also (orange, pink, brown, and purple). Fourth, the referential salience of the "primary" and "secondary" foci appears equivalent. Effectively, subjects were as able to distinguish between a "pure", and "off" orange, pink, brown, and purple as they were between a "pure" and "off" red, yellow, green, and blue.

Two interesting points are raised by the results of the hue tests-namely, how to account for the referential status of the "secondary" foci, and how to account for the absence of difference between subjects' performances on this set and the "primary" set.

It is notable that attempts have been made to provide a theoretical basis for the referential status of the "primary" foci in psychophysical and physiological data (Bornstein, 1973; Rosch, 1975, 1977). It is equally notable that this fails completely to account for either the referential status of the "secondary" foci or the very existence of the "secondary" categories. If, as Rosch (1975) suggests, color categories form around cognitively salient, probably physiologically determined, prototypes (or foci)and the evidence from a variety of learning and memory tasks performed on members of diverse cultures tends to favor this conjecture (e.g., Heider, 1971,1972 ) - then it is worth entertaining the hypothesis that the "secondary" categories may be similarly formed. After all, information on postretinal color processing is extremely limited, particularly at the level of the visual cortex. That an opponent system operates at a middle processing level, which corresponds well with the notion of four "primary" chromatic categories, does not preclude the operation of further and later systems."

Finally, certain theoretical implications may be noted for the structuring of color-descriptive systems. In attempting to provide descriptive models of color space, systems such as the Munsell (Munsell, 1961) and Natural Color System (NCS; Hård, 1970, 1975) employ segmentations of color space that presuppose their representativeness of human color classifications. However, on the basis of the present re- 
sults, and those from earlier studies noted above, the adequacy of these representations appears questionable, certainly regarding the number and nature of chromatic categories employed. This is particularly apparent for the recently developed NCS, given the explicitly phenomenological rationale underlying its design.

\section{REFERENCES}

Berlin, B., \& KAy, P. Basic color terms. Berkeley: University of California Press, 1969.

BonNSTE IN, M. H. Color vision and color naming: A psychophysiological hypothesis of cultural difference. Psychological Bulletin, 1973, 80, 257-285.

British Standards Institution. Illuminant for colour matching and colour appraisal (B.S. 950, Pt. 1). London: British Standards Institution, 1967.

Brown, R. W., \& LenNeberg, E. H. A study in language and cognition. Journal of Abnormal and Social Psychology, 1954, 49, 454-462.

DE Valors, R. L., \& DE VAlois, K. K. Neural coding of color. In E. C. Carterette \& M. P. Friedman (Eds.), Handbook of perception (Vol. 5). New York: Academic Press, 1975.

Handel, S., \& Garner, W. R. The structure of visual patiern associates and pattern goodness. Perception \& Psychophysics, $1966,1,33-38$.

HARD, A. Qualitative attributes of colour perception. In M. Richter (Ed.); Colour 69: Proceedings of the First Congress of the International Colour Association. Göttingen: Muster-Schmidt, 1970.

HÁRD, A. A descriptive color order system with application for environmental design. Man-Environment Systems, 1975, 5, 161-167.

HEIDE R, E. R. "Focal" color areas and the development of color names. Developmental Psychology, 1971, 4, 447-455.

HeIDER, E. R. Universals in color naming and memory. Journal of Experimental Psychology, 1972, 93, 10-20.

Hollanden, M., \& Wolfe, D. A. Nonparametric statistical methods. New York: Wiley, 1973.

Ishinara, S. Tests for colour blindness. Tokyo: Kaneshara Shuppan, 1969.

LAKoFF, G. Hedges: A study in meaning criteria and the logic of fuzzy concepts. Papers from the Eighth Regional Meeting, Chicago Linguistics Society. Chicago: University of Chicago Linguistics Department, 1972.

LEE, T. R. Perceived distance as a function of direction in the city. Environment and Behavior, 1970, 2, 40-51.
Mervis, C. B., Catlin, J., \& Rosch, E. Development of the structure of color categories. Developmental Psychology, 1975, 11, 54-60.

Munsell, A. H. A color notation. Baltimore: Munsell Color Co., 1961. (Originally published, 1905.)

Padgham, C. A., \& Saunders, J. E. The perception of light and colour. London: Bell, 1975.

RAY, V. F. Human color perception and behavioral response. Transactions of the New York Academy of Sciences, 1953, 16, 98-104.

Rosch, E. Natural categories. Cognitive Psychology, 1973, 4, 328-350.

Rosch, E. Cognitive reference points. Cognitive Psychology, $1975,7,532-547$.

Rosch, E. Human categorization. In N. Warren (Ed.), Studies in cross-cultural psychology (Vol. 1). New York: Academic Press, 1977.

Rosch, E., \& Mervis, C. B. Family resemblances: Studies in the internal structure of categories. Cognitive Psychology, 1975, 7, 573-605.

Rosch, E., Mervis, C. B., Wayne, D. G., Johnson, D. M., \& Boyes-Braem, P. Basic objects in natural categories. Cognitive Psychology, 1976, 8, 382-439.

Rosch, E., Simpson, C., \& Miller, R. S. Structural bases of typicality effects. Journal of Experimental Psychology: Human Perception and Performance, 1976, 2, 491-502.

TVersky, A. Features of similarity. Psychological Review, 1977, 84, 327-350.

Walraven, P. L. Theoretical models of the colour vision network. In Colour 73: Proceedings of the Second Congress of the International Colour Association. London: Adam Hilger, 1973.

Werthelmer, M. Numbers and numerical concepts in primitive peoples. In W. D. Ellis (Ed.), A source book of Gestalt psychology. New York: Harcourt, Brace, 1938.

Whitfield, T. W. A., \& Slatter, P. E. The effects of categorization and prototypicality on aesthetic choice in a furniture selection task. British Journal of Psychology, 1979, 70, 65-75.

ZEKI, S. The representation of colors in the cerebral cortex. Nature, 1980, 284, 412-418.

\section{NOTE}

1. For recent information on the nature of color-responsive cells in the visual cortex, see Zeki (1980).

(Received for publication April 23, 1980; revision accepted October $21,1980$. ) 